\title{
Duplication of Subject Entries in the Catalog of a University Library and Bibliographies in English Literature
}

Mr. Simonton is chief of the catalog department, University of Minnesota Library.

\section{The Clientele of the University Library}

$\mathrm{D}$ URING the period of the development of the dictionary card catalog in American libraries, a number of theories have been advanced as to the services which it can render effectively, and as to the proper methods of implementing those services. In some cases these theories have not been consistent with the demands which are made on the catalog by the public, for whom it is theoretically constructed. In earlier years librarians were too busy discovering the many possibilities inherent in the dictionary card arrangement itself to give serious thought to the value of the various services made possible by that arrangement. Recent years, however, have seen the beginning of systematic attempts to measure the actual uses made of the catalog.

The present study represents an examination of one of the services provided by most large college and university libraries (for practical purposes, the term may be broadened to include most of those libraries described as "research libraries"), namely, the inclusion in the card catalog of a complete file of all the works held by the library on any given subject. However, before examining this service, the different types of users of these libraries should be defined. They may be divided into two broad groups, hereafter designated in this study as "re- search worker" and "general reader." By the former is meant those persons. interested in an exhaustive study of a given subject, including faculty members, graduate students and visiting scholars. The term "general reader" includes both the undergraduate students of the liberal arts college which is part of the university, and also the research worker who is seeking information on a subject outside his sphere of major interest. The undergraduate student usually desires to have the entire literature of his subject made available to him; the research worker either consults "reserve" material containing assigned readings or calls for books of an introductory nature on a subject of interest.

The research worker's needs require the university librarian to develop the library's resources in certain fields of specialization as thoroughly as possible-by acquisition, interlibrary loan, and photographic duplication. Further, the library must provide the bibliographical apparatus required for intensive study of a subject. As the university library grows in size, however, it becomes increasingly necessary to make provision for special services to the general reader which are not found necessary in the smaller college library. In a large university library the general reader is often at a loss in choosing a book because of the abundance of material available, much of which is too specialized to satisfy his needs. Some of the larger libraries have sought to solve this 
problem by establishing separate "undergraduate" or "college" libraries, with the book stock limited to carefully chosen general and introductory works on all subjects.

\section{The Nature of the Subject Catalog}

In considering the question of the nature of the subject catalog, the demands made on it by the users of the library should be kept in mind. It has been pointed out that the research worker should possess an exhaustive knowledge of the literature of his field of interest. Either he already has that knowledge or he is interested in acquiring it. In the former case, he has no need of a subject index of any sort (except to keep abreast of current material); in the latter, he wants to know about everything written on the subject. In this case also, the subject catalog is of little use to him because it is limited to the material available in one library and because, in general, it catalogs by form and not by content. To learn everything written on a particular subject, the research worker must search every available bibliography and the subject catalog represents only an intermediate step. Until libraries find some solution along the lines of Fremont Rider's microcard, the needs of the research worker will remain unsatisfied. Furthermore, not only does the bibliography recognize no limitations of location or form of material, but it is more aware of the method of the research worker than the catalog can hope to be, at least in its present form. Swank's study ${ }^{1}$ has shown that the doctoral student in English literature finds his research directed more effectively by the bibliography than by the library subject catalog and classification scheme, even for materials contained in the library, simply because the bibliographer takes the

I Swank, Raynard C. The Organization of Library Materials for Research in English Literature. Unpub. lished Ph.D. thesis, University of Chicago, 1944. A summary of this study appeared in Library Quarterly $15: 49-74$, January 1945 . reader's point of view and the cataloger does not.

On the other hand, the question of service to be provided to the general reader poses a problem which is the exact opposite to that raised by the needs of the research worker. The general reader wants only a few well-chosen general works on any given subject; if an undergraduate library exists and if it includes a good subject catalog, it will meet most of his needs. If, however, the general reader must use the same cata$\log$ as the research worker, the situation is very different. Present-day university library subject catalogs are generally produced to meet what are assumed to be the needs of the research worker, but as a matter of fact, the available evidence suggests that the subject catalog is used far more frequently by the undergraduate than by the graduate student or faculty member. Miller's study of the use of the card catalog at three university libraries ${ }^{2}$ indicated that the graduate student and faculty member used the catalog twice as often for locating a particular book as for choosing a book on a given subject, whereas the ratio of use by the undergraduate student was virtually one to one. As a result, he recommended development of the subject catalog to meet undergraduate needs and vocabulary. Brown's investigation of the use of the subject catalog by graduate students in sociology at the University of Chicago ${ }^{3}$ found that they used it only as a "supplementary tool" to professors' suggested reading lists or to bibliographies contained in journals or books. A recent report by Nyholm on the reaction to the change from dictionary catalog to divided catalog at the University of California ${ }^{4}$ showed that the faculty ap-

\footnotetext{
2 Miller, Robert A. "On the Use of the Card Catalog." Library Quarterly, I $2: 629-37$ July 1942. of Brown, Margaret C. "The Graduate Student's Usse of the Subject Catalog."
braries 8:203-08, July i 1947.

'Nyholm, Amy Wood. "California Examines Its Divided Catalog." College and Research Libraries 9:195-201, July I 948 .
} 
proved of the change because it separated the author entries, which they used almost exclusively, from the little-used subject entries. The students also liked the division because it made the subject entries more directly available than before. In many instances they had not even been aware of their existence. However they still found the subject catalog difficult to use because of the great number of entries under many headings.

\section{Coordination of the Subject Catalog with Existing Subject Bibliographies}

The evidence of these studies suggests that the subject catalog of the large university library, which attempts to provide a subject approach to every separately issued work contained in the library, often fails to serve either the research worker or the general reader effectively. This failure will occur most frequently in the case of broad subject headings, such as "English literature," "Economics," and "Political science." If it is assumed that large accumulations of cards under such headings are of limited use to the research worker because they do not constitute a complete bibliography of the subject, and are of little use to the general reader because their great number renders effective selection of desired material difficult, the necessity of their inclusion in the catalog may be questioned. Elimination of unnecessary subject cards would result in reducing the present size of the catalog, thereby minimizing present difficulties of physical arrangement. Further, in the future the making of subject entries as material is acquired may be reduced, thereby effecting economies in the number of cards to be made and filed.

Two of the most common objections to eliminating subject cards from the catalog have been ( $\mathrm{I}$ ) that the catalog should con- tain a record of all the material in the library on a given subject, and (2) that the catalog should bring together material scattered through many bibliographies and material not available in any bibliography, due either to its rarity or to its recency. As a result, the catalog helps to identify items inadequately cited, which may be checked under subjects as well as under author. These two theories have been propounded most frequently by reference librarians, and it is doubtless true that their arguments are based on extensive use of the catalog in this way. However, as has been pointed out, it is impossible for the catalog to contain a complete record of all the resources of the library on a given subject unless the library is willing to resort to detailed analysis of periodicals, series, reports and other similar publications. It was the purpose of the present study to secure a partial answer to the second of these arguments. If it can be shown that in certain subject fields the subject catalog represents in large measure duplication of bibliographies already in existence, the second argument will lose much of its validity as far as those subject fields are concerned. To date, only two systematic studies of this sort of duplication have been made.

The first of these ${ }^{5}$ determined the relative efficiency of the card catalogs of several large college and university libraries and of government indexes in making available the contents of federal documents, and found that use of the catalog had to be supplemented by use of the indexes if a significant number of the important works was to be found. The second study, Schloeder's "Selective Subject Cataloging,",

\footnotetext{
5 Campbell, Grace A. "A Study of the Extent to which Existing Printed Government Indexes and Catalogues Can Replace the Card Catalogue in Making the Contents of Federal Documents Available," Bulletin Contents of Federal Documents Avanlable. Bulletin of the Oklahoma Agricultural and Mechanical College, ibrary Bulletin No. 7, vol. 36, no. I7, November 1939 - Schloeder, Elmer. "Selective Subject Cataloging A Preliminary Analysis of a Possible Means of Reduc.
} 
found that 73.2 per cent of the titles listed under certain medical subject headings in the dictionary catalog of the Chicago University Libraries were also listed in the Index-Catalogue of the Surgeon General's Office (another I3.6 per cent being of too recent a date to permit inclusion in the bibliography).

\section{Scope and Method of the Present Study}

The present study was undertaken for the purpose of ascertaining similar information in the field of English literature. Two subdivisions of this field were chosen for study, namely, the Shakespeare literature and the Chaucer literature. The catalog chosen for study was the main, or "general," catalog of the Columbia University Libraries. This is a union catalog of all the holdings of the libraries in the Columbia system, with the exception of those of the Teachers' College Library and aportion of those in the Law Library. As such, it includes main entries for all materials in all libraries, main and departmental, and omits secondary entries for works on specialized legal and medical subjects only. As of July I, I947, the total number of volumes in the Columbia University Libraries was $\mathrm{I}, 806,375 ;^{7}$ at that time the catalog consisted of 2660 trays, containing approximately 2,660,000 cards (figured on the basis of Iooo cards per tray). For nearly 25 years it has been the policy of the library to assign subject headings to every item cataloged as a separate, regardless of size or format. Analytics have been made very sparingly. Prior to 1920 it was the practice to bind several pamphlets or other minor works in one volume, giving main entries for each item, but only one subject entry for the volume as a whole. In later

ing the Bulk of the Catalog in the University Library." Unpublished M.A. thesis, University of Chicago, I 945 7 Cf., Annual Report, I946-47, of Altha E. Terry, catalog librarian, Columbia University I.ibraries. years many of these pieces have been recataloged so as to provide subject entries for each individual item.

In investigating the material on Shakespeare found in the Columbia catalog, the following three broad subject headings ${ }^{8}$ were chosen for study as being headings likely to be consulted by the reader: Shakespeare (not subdivided); ShaKeSPEARE-BIOGRAPHY; SHAKESPEARECRITICISM AND INTERPRETATION.

Under these headings and under the heading investigated later (CHAUCER), Columbia has included entries for all materials cataloged separately, regardless of type of material or location in the library system. The only exception for the material under Shakespeare is a single entry for three "pamphlet volumes," which include a total of I6 titles. For purposes of this study, it was decided to treat these works as if they had been given separate subject entries, in view of Columbia's present policy, as outlined above. Hitchcock's study ${ }^{9}$ found I4 types of material for which over 50 per cent of the libraries questioned agreed in omitting subject entries. Of these only two are applicable to the subject under study here: pamphlet collections and dissertation collections. The findings of this study of the Columbia catalog may, therefore, be applied by other libraries in the light of their method of handling these types of materials, as compared to the Columbia policy of including subject entries for them.

\section{Quantitative Findings}

All titles listed under the three subject headings indicated above were searched in

\footnotetext{
8 Throughout this study capital letters are used to indicate the catalog's subject headings, as opposed to the use of quotation marks to indicate those of the bibliographies; in both cases, dashes are used to in-

dicate subdivision of heading.
9 Hitchcock, Jennette. "The Coverage of Material ${ }^{9}$ Hitchcock, Jennette. "The Coverage of Material
under the Subject Entries of the Dictionary Catalog in American University Libraries." Unpublished M.A. thesis, University of Chicago, 1938 . A summary of this study appeared in the Library Quarterly io:69. 94, January I940.
} 
the following bibliographies to determine their availability to a reader interested in a comprehensive listing of works on Shakespeare: Ebisch and Schucking's A Shakespeare Bibliography (I93 I and supplement 1935), the Shakespeare Association of America's Annual Bibliography of Shakespeariana, I925-1945, Jaggard's Shakespeare Bibliography (I9II), and the bibliographies included in the Shakespeare Jahrbuch, 1865-1940. (These biblographies are hereafter referred to as "Ebisch," "S.A.A.," "Jaggard," and "S.J.," respectively.) The bibliographies were checked in the order listed above, which seemed the one most likely to result in an effective search of the Shakespeare literature as of 1947 , because of the limitations of the various bibliographies. Items found in any one bibliography were not searched in those checked subsequently, since it was considered that any comparison of the bibliographies themselves was extraneous to and beyond the scope of the present study. Of 502 titles listed in the Columbia catalog, 457 , or 9I per cent, were found to be listed in the bibliographies -242 in Ebisch, 58 in S.A.A., 84 in Jaggard, and 73 in S.J.

The second heading chosen for study was selected because of the existence of a much more comprehensive single-volume bibliography than is the case for Shakespeare. Hammond's bibliography of Chaucer, together with its two supplements by Griffith and Martin, supplies a comprehensive listing of the material in this field published through I 933. In an attempt to bring the bibliography up to date, titles not found in these three works were checked in Wells' bibliography of writings in Middle English. The procedure outline above for analyzing the materials relating to Shakespeare was followed for comparing the duplication in Chaucer titles between the Columbia cata$\log$ and the bibliographies. Of 142 titles listed in the Columbia catalog, I 33, or 94 per cent, were found to be listed in the bibliographies-123 in Hammond, Griffith and Martin, and Io in Wells. Three of the bibliographies used in this study-S.A.A., S.J., and Wells - are admittedly periodical publications and thus do not present the material included in as convenient a form as does the catalog. However, the question involved in this study is not one of convenience per se. The catalog is obviously easier to use for those titles to which subject headings have been assigned. In this connection, the possibility of use of the shelflist as a classified catalog which duplicates to a certain extent the work of the subject catalog should also be kept in mind. The question is rather, how much material does the subject catalog locate which the bibliographies do not also make available, in light of the assumption that the research worker must always consult the bibliographies for a complete listing of material of interest?

\section{Qualitative Findings}

At this point it is appropriate to consider the qualitative value of the bibliographies. Of the several works examined, only two, S.J. and Wells, represent less detailed subject cataloging than the Columbia catalog. Both employ only a single heading for the material on Shakespeare and Chaucer, respectively. The subdivisions of the other bibliographies are basically similar to those of the catalog. Jaggard and S.A.A. are directly comparable to the catalog in that many subdivisions are used and they are arranged alphabetically. However Ebisch, Hammond, Griffith and Martin, while including even more subdivisions than the catalog, employ a classified arrangement which brings together material under major headings.

The 242 titles common to the catalog and to Ebisch were checked in the latter by 
major subdivision in order to compare the subject cataloging of the two tools and to ascertain the number of titles made available under each subdivision. This comparison of the qualitative value of the Columbia cata$\log$ and of Ebisch indicated two things. First, and more important, under each of the broad subjects chosen for study, the single bibliography listed a number of titles which should be sufficient for the general reader. For example, under the subdivisions "Shakespeare's life" and "Shakespeare's personality," a total of 69 titles was listed, including 27 under "The most important biographies (including general studies of Shakespeare's life and works)." This may be compared with the catalog's heading SHAKESPEARE-BIOGRAPHY, under which 52 titles were entered. In this connection it should be remembered that the bibliography is consciously selective as compared with the catalog, resulting in a list of titles more likely to be of value to the general reader.

Second, it was found that the heading used in the bibliography was in virtually every case more specific or more indicative of the book's actual contents than that of the catalog. Thus, of the 242 titles, 70 were listed under equivalent headings in the cata$\log$ and in the bibliography. Another I 39 titles were listed in the catalog under SHAKESPEARE. Since the bibliography contains no such broad heading as this, all of these titles were listed under a more specific heading. The remaining 33 books, listed under different headings in the catalog and in the bibliography, were examined individually (by reading the preface to discover the author's purpose and by scanning the contents) to ascertain which tool provided a better subject heading. The bibliography proved better in 30 cases, leaving only three titles out of 242 in which the catalog heading was better than that of the bibliography.

\section{Conclusions and Recommendations}

This study indicates that the practice of assigning subject headings to all items cataloged as separates in the Columbia University Libraries has resulted in files of titles under certain broad Chaucer and Shakespeare headings which represent almost complete quantitative duplication of the entries in certain basic bibliographies on the same subjects. Further, the subject cataloging of the bibliographies is more specific than that of the catalog for titles common to both.

The implication of these findings in regard to the use of the subject catalog by the research worker and by the general reader are plain. For the research worker the catalog lists only a handful of titles not available in the bibliographies, with which he is presumably already familiar, due primarily to two considerations: few analytics and only those titles held by a single library are included. For him the catalog would provide better service if it listed only those titles not already available in the bibliographies. He could thereby ascertain directly the titles held by the library with which he is likely to be unacquainted. For the general reader, the catalog lists too many titles for effective selection of the book to satisfy his particular needs. With the exception of the most recent titles, the bibliographies provide better guidance since those of first importance (Ebisch for Shakespeare and Hammond and Martin for Chaucer) provide annotations to guide him in his choice of an individual title.

In the light of these findings, certain recommendations may be made concerning the library's policy of including subject entries in the catalog for works which are already available through bibliographies. If it is assumed that a smaller catalog is desirable, the library can achieve this end in one of two ways. The first method would 
be to eliminate all entries for titles listed in the bibliographies, making a general reference to these works under the subject heading in question. This would involve a purely mechanical operation and would leave in the catalog only a few older titles and all of those titles published after the effective date of the latest bibliography. It would seem to be an effective method of serving the needs of the research worker, but it would only partially satisfy those of the general reader.

In order to fulfil its obligations to the general reader, the catalog should include a certain basic number of titles of first importance, not limited by date of publication. The selection of these titles may be made either by specialists on the library staff, the faculty, or by cooperation between these two groups. The bibliography might well furnish a starting point for selection of those older titles which are still of first importance. As more recent titles are acquired by the library, they would be examined to determine their qualifications for inclusion in this group. The subject file would be broken into two parts and an introductory guide card placed at the beginning of the file reading:

For a comprehensive listing of material on this subject see the following bibliographies:

This catalog lists in File A a selected group of titles of first importance and in File $B$ all titles held by the library which are not included in the bibliographies above.

This procedure would in some ways involve more work than the present policy of indiscriminate listing of all works on a given subject. Further, it would require some training of the catalog users by reference or cataloging assistants or, at least, a different kind of training from that which they now receive. It should result in a more meaningful catalog, especially for the general reader, who, according to the available evidence, uses the subject catalog far more frequently than the research worker.

The extent to which the library may find it possible to reduce the size and increase, the effectiveness of its subject catalog, will of course be limited by the number and nature of subject bibliographies available. This study has been concerned only with those bibliographies of value in certain areas of English literature. For any large-scale program it will be necessary to make similar investigations in other subject fields. The most efficient method of carrying out this work would seem to be through the establishment of something like the "bibliographical service department" proposed most recently by Swank, ${ }^{10}$ a department which would be responsible for the correlation of the subject catalog and subject bibliographies.

The next stage is that of developing subject bibliographies in fields where they do not now exist. At present Harvard is planning to produce subject bibliographies based on its extensive holdings, to be used in place of the card catalog. Cooperation of other scholarly libraries in this project would result in bibliographies of first importance in many subject fields. Further, this project should be coordinated with Ellsworth's proposals concerning centralized cataloging for scholarly libraries, ${ }^{11}$ which envision the creation of printed cumulative union author catalogs, including as a by-product printed subject bibliographies, both comprehensive and selective-annotated. Only by providing such services will the large university library meet the needs of its two types of users-the research worker and the general reader.

10 Swank, op. cit., p. ${ }^{73-74 .}$. Scholarly Libraries." Library Quarterly 15:237-43, July $\mathbf{x} 945$. 